\title{
Students' sense of belonging in technical/vocational schools versus academic schools: The mediating role of faculty trust in students
}

Paper presented at the Midterm Conference 2010 of the Sociology of Education Research

Network of the European Sociological Association

Panteion University of Social and Political Sciences, Athens, Greece

30 September - 1 October 2010

Prof. dr. Mieke Van Houtte

Department of Sociology

Research Group CuDOS

Ghent University

Korte Meer 3-5

9000 Gent

Belgium

Mieke.VanHoutte@UGent.be drs. Dimitri Van Maele

Department of Sociology

Research Group CuDOS

Ghent University

Korte Meer 3-5

9000 Gent

Belgium

Dimitri.VanMaele@UGent.be 


\section{Authors: Mieke Van Houtte \& Dimitri Van Maele}

\section{Presenting author: Dimitri Van Maele}

The large-scale research into the consequences of educational stratification has dealt with several educational outcomes, such as students' academic attitudes, engagement, and achievement. This research, however, has seldom considered outcomes pertaining to the well-being of students, such as the extent to which students in different tracks feel embedded in or alienated from their school communities. Yet, ethnographic case studies show that lower track students often get alienated from school, resulting in study disengagement and poor achievement. Moreover, it has been demonstrated that teachers associate in a less positive way with students in lower tracks. Students are treated in a less interesting and challenging way, discipline and control are stressed to a higher extent, and teachers in technical/vocational schools show to trust their students less than their colleagues in schools offering academic tracks. Teachers' trust in students is a form of teacher-based social capital available to students that indicates the nature of in-school intergenerational bonding and the presence of a supportive educational environment. Given that students' connectedness to school is related to a supportive student environment, students' sense of school belonging is expected to be stronger in schools where faculty members trust the students.

From that perspective, this study examines Flemish students' sense of belonging in the different secondary school types and the role faculty trust in students plays herein, making use of stepwise multilevel analyses (HLM6) on data of 3475 students and 754 teachers in 28 technical/vocational schools and 3376 students and 461 teachers in 22 academic schools. The multilevel analyses control for student and school characteristics. Students' sense of school belonging was measured using a Dutch translation of Goodenow's Psychological Sense of School Membership scale, whereas a 
measure for faculty trust in students was based on the teacher trust scales developed by Hoy and Tschannen-Moran.

The results show that students in technical/vocational schools have a significant lower sense of belonging at school than students in academic schools. This association holds controlling for several school features—size, sector, ethnic composition—and student features—gender, age, socioeconomic status, migrant origin, parental support and prior achievement—, but decreases firmly and gets nonsignificant when taking into account faculty trust in students.

Our findings indicate that teachers' trust in students differs according to the track in which the teacherstudent relationships take place, and that this mechanism is responsible for the students' lower sense of belonging in technical/vocational schools compared to academic schools. Therefore, our findings show that teachers fulfill a crucial role in the divergent nature of students' social integration across different types of schools. In demonstrating the mediating role of the teachers' trust relations with students—considered as a school feature—in the association between tracking and students' sense of belonging, this study makes a relevant contribution to revealing the mechanisms through which tracking affects student outcomes. 